\title{
Сорбция рутина и танина на активном угле БАУ-А
}

\author{
Подолина Е.А. ${ }^{1,2,3}$, Ханина М.А. ${ }^{2}$, Мухин В.М. ${ }^{3}$, Рудаков О.Б. ${ }^{4}$, \\ Небольсин А.Е. ${ }^{5}$, Козлов А.Т. \\ ${ }^{1}$ ФГУУ ВО «Электростальский институт (филиал Московского политехнического университета)», \\ Электросталь \\ ${ }^{2}$ ОГОУ ВО Государственный гуманитарно-технологический университет, Орехово-Зуево \\ ${ }^{3}$ АО ЭНПО «Неорганика», Электросталь \\ ${ }^{4}$ ФОУ ВО «Воронежский государственный технический университет», Воронеж \\ ${ }^{5} О А О$ «Партнер», Воронеж \\ ${ }^{6}$ Военно-воздушная академия имени Н.Е.Жуковского и Ю.А.Гагарина, Воронеж
}

Поступила в редакцию 24.10.2018 г.

DOI: https://doi.org/10.17308/sorpchrom.2018.18/619

Исследована адсорбция и десорбция природных полифенольных соединений (ПФС) - рутина и танина из водных растворов и водно-этанольных экстрактов травы василька синего на активном угле марки БАУ-А. Рассчитаны физико-химические параметры адсорбции ПФС на активном угле БАУ-А с использованием уравнений Ленгмюра, Фрейндлиха, Дубинина-Радушкевича и БЭТ. При использовании в качестве элюента метанола или бинарной смеси вода - этанол (47 об. \%) достигается 80\%-я десорбция ПФС. Полученные экспериментальные данные позволяют рекомендовать активный уголь БАУ-А как эффективный сорбент для извлечения природных фенольных соединений из водноэтанольных экстрактов с последующим их выделением.

Ключевые слова: активный уголь, адсорбция, десорбция, природные полифенольные фенольные соединения, рутин, танин, экстракты травы василька синего.

\section{Sorption of rutin and tannin on active carbon BAU-A}

\author{
Podolina E.A. ${ }^{1,2,3}$, Khanina M.A. ${ }^{2}$, Mukhin V.M. ${ }^{3}$, Rudakov O.B. ${ }^{4}$, \\ Nebolsin A.E. ${ }^{5}$, Kozlov A.T. ${ }^{6}$ \\ ${ }^{l}$ FGOU VO «Electrostal Institute (branch of Moscow Polytechnic University)», Elektrostal \\ ${ }^{2}$ OGOU VO State Humanitarian-Technological University, Orekhovo-Zuevo \\ ${ }^{3}$ AO ENPO "Neorganika", Elektrostal \\ ${ }^{4}$ FGOU VO "Voronezh State Technical University", Voronezh \\ ${ }^{5} \mathrm{OAO}$ "Partner", Voronezh \\ ${ }^{6}$ Air force Academy named after Professor N. E.Zhukovsky and Y. A. Gagarin, Voronezh
}

Natural phenolic compounds (NPC) are the most important biologically active additives (BAA) and a part of drugs, biologically active additives (BAA) and water-ethanol extracts. AC BAU-A was used to isolate NPC from aqueous-alcoholic extracts. The purpose of this research is to study the adsorption and desorption capacity of NPC (for example, rutin and tannin) on the active carbon BAU-A.

The adsorption of NPC was carried out from solutions of standard samples and the resulting waterethanol extracts on the ultrasonic unit on active carbon (AC) BAU-U with the particle size of 1.0-3.5 mm. It was experimentally proved that the carbon fraction with the particle size $1.0-1.5 \mathrm{~mm}$ most fully adsorbs the studied NPC (93-95\%) during 15-30 minutes. The obtained adsorption isotherms of NPC on BAU-A belong to the L-type according to the Gibbs classification and confirm the physical mechanism of adsorption. 
The adsorption isotherms were used to calculate the physicochemical parameters using the theory of monomolecular adsorption (Freindlich, Langmuir equations), polymolecular adsorption (BET model), and the theory of volume filling of micropores (Dubinin-Radushkevich equation). The obtained values of the Gibbs energy confirm that natural phenolic compounds are adsorbed in micropores due to van der Waals forces, and the surface functional groups of the AC form hydrogen bonds of the sorbate-sorbent.

The desorption of NPC was carried out under dynamic conditions in a column $360 \mathrm{~mm}$ long, $15 \mathrm{~mm}$ in diameter, and an AC layer height of $80 \mathrm{~mm}$. Polar individual solvents (water, methanol), an aqueous solution of $\mathrm{HCl}$, and a binary mixture of water and ethanol $\left(\varphi_{2}=0.47\right)$ were used as eluting solutions. The most effective eluting solution for isolating (75-80\%) NPC from the sorbent is methanol or a water-ethanol binary mixture.

Thus, on the basis of the obtained experimental data, it was shown that AC BAU-A has a high adsorption capacity with respect to NPC. The use of a binary mixture of water-ethanol or methanol as an eluting solution makes it possible to isolate almost $80 \%$ of NPC from the BAU-A sorbent (in terms of rutin and tannin). Active carbon BAU-A manufactured according to GOST 6217-74 (OA ENPO "Neorganika", Elektrostal, Moscow region) is recommended for adsorption of NPC from water-ethanol extracts with subsequent desorption.

Keywords: active carbon, adsorption, desorption, natural polyphenolic phenolic compounds rutin, tannin, extracts of cornflower blue grass.

\section{Введение}

Природные полифенольные соединения (ПФС), такие как рутин и танин, используются в фармацевтической промышленности для производства различных лекарственных форм и биологически активных добавок [1,2].
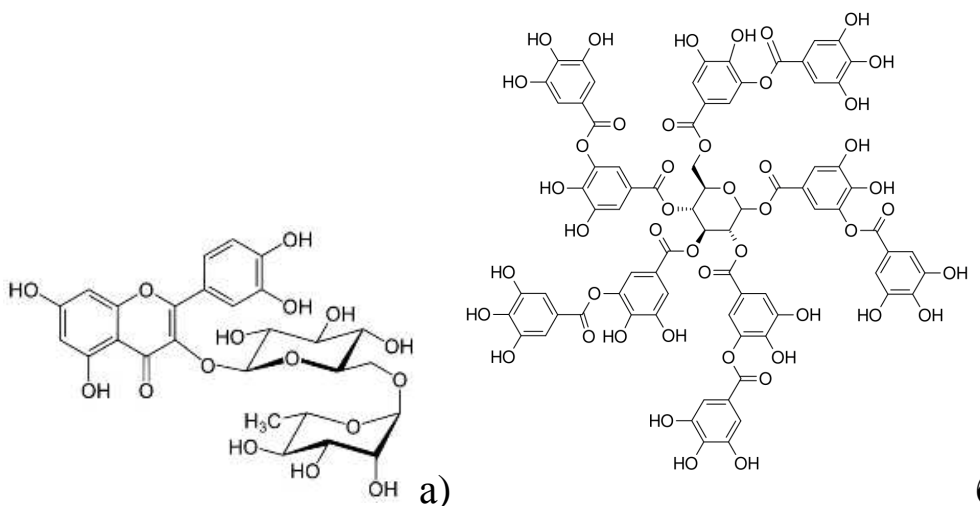

Структурные формулы: а) рутин, б) танин

Промышленным сырьем для выделения ПФС могут служить цветки софоры японской или культивируемых сортов травы гречихи [1,2], а танина - кора дуба, трава горца почечуйного $[3,4]$. В этом плане представляет интерес трава василька синего, во всех морфологических частях которого содержатся как рутин, так и танин $[5,6]$.

ПФС традиционно извлекают из растительного сырья с помощью различных методов твердожидкостной экстракции. В качестве экстрагентов применяют различные бинарные водно-органические смеси, чаще всего смеси на основе этанола [7-10].

Для выделения, концентрирования и очистки ПФС из полученных экстрактов используют различные сорбенты, например, разнообразные марки активных углей [1] и даже наноразмерные алмазы [11,12].

\section{Теоретическая часть}

Активные угли достаточно давно и широко используются как сорбционные препараты в здравоохранении и фармацевтической промышленности. Основное на- 
значение - очистка и выведение токсичных веществ из организма человека - гемо- и энтеросорбция [13] или очистка сточных вод предприятий фармацевтической промышленности $[14,15]$. В настоящей работе в качестве сорбента выбран промышленный активный уголь марки БАУ-А с размерами частиц от 1 до 3.6 мм, соответствующий требованиям ГОСТ 4453. Распределение частиц по размерам показано на рис.1, установлено, что наибольшая доля частиц (63 масс.\%) имеет размер 2.0-2.8 MM.

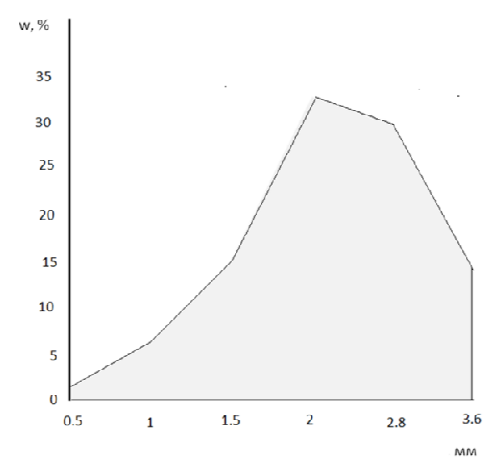

Рис. 1. Гистограмма распределения частиц активного угля БАУ-А

Для активного угля этой марки характерно преимущественное развитие микро- и макропор, за счет чего он способен эффективно сорбировать молекулы сравнительно крупных размеров, таких как рутин и танин [14,15]. Основные физикохимические свойства БАУ-А приведены в табл. 1.

Таблица 1. Физико-химические свойства БАУ-А [1, 12]

\begin{tabular}{|c|c|}
\hline Параметр & \\
\hline Адсорбционная активность по йоду, \% & 60 \\
\hline Адсорбционная активность по метиленовому голубому, мг $/ \Gamma$ & $60-70$ \\
\hline Суммарный объем пор по $\mathrm{V}_{\Sigma}, \mathrm{cm}^{3} / \Gamma$ & $1.65-1.8$ \\
\hline Предельный объем сорбционного пространства, $\mathrm{W}_{\mathrm{S}}, \mathrm{cm}^{3} / \Gamma$ & $0.30-0.35$ \\
\hline Объем, см ${ }^{3} / \Gamma$ & $0.22-0.25$ \\
микропор & $0.08-0.1$ \\
мезопор & $0.35-1.45$ \\
макропор & $0.21-0.24$ \\
\hline Предельный адсорбционный объем микропор, $\mathrm{cm}^{3} / \Gamma$ & $0.56-0.6$ \\
\hline Размер полуширины микропор, нм & $400-500$ \\
\hline
\end{tabular}

Целью представленной работы явилось изучение процессов сорбции и десорбции ПФС на примере рутина и танина на активном угле БАУ-А.

\section{Эксперимент}

Реактивы: этанол, раствор для наружного применения и приготовления лекарственных форм с концентрацией 95 об.\% (ПХФК ОАО «Медхимпром»); метанол, квалификации х.ч. (массовая доля 99.5\%); растворы стандартных образцов (ГСО) рутина и (PCO) танина: водно-спиртовой раствор рутина с концентрацией 0.1 моль/дм ${ }^{3}$; водный раствор танина с концентрацией 0.1 моль/дм ${ }^{3}$; бинарная смесь - вода - этанол, с объемной долей этанола 47\%; водно-этанольные экстракты травы василька синего, полученного методом однократной твердожидкостной экстракциии на УЗ-установке [8]. 
Сорбент БАУ-А (ГОСТ 6217-74) изготовлен в НПО «Неорганика», г. Электросталь Московской области.

Оборудование: количественное определение рутина и танина в растворах осуществляли методом УФ-спектрофотометрии (спектрофотометр UNICO, модель 2800), аналитическая длина волны для рутина 361 нм, для танина - 275 нм; перемешивание раствора и сорбента осуществляли на вибросмесителе (Shaker 3.02), с частотой вращения v=150 об/мин обеспечивающей ламинарное движение потока жидкости; водно-этанольные экстракты травы василька синего получали на экспериментальной УЗ-установке, созданной на базе научно-исследовательской лаборатории конструкторского бюро МКС (фирмы ОАО «Партнер», г. Воронеж), частота УЗизлучения 22-23 кГц.

Методика выполнения эксперимента: исследования сорбции проводили в статических условиях из растворов ГСО рутина, растворов РСО танина и водноэтанольных экстрактах, полученных из травы василька синего при температуре $22 \pm 2^{\circ} \mathrm{C}(293 \pm 2 \mathrm{~K})$, постоянном перемешивании и $\mathrm{pH}=7$.

Для определения времени установления адсорбционного равновесия между сорбентом и сорбатом через каждые 5 мин отбирали пробу контактного раствора и спектрофотометрическим методом определяли концентрации сорбатов (рутин и танин). Десорбцию ПФС из сорбента осуществляли в динамических условиях: в колонку длиной 360 мм, диаметром 15 мм помещали активный уголь (высота слоя

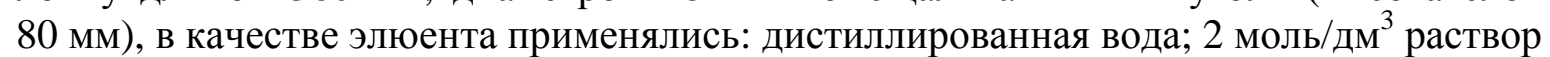
$\mathrm{HCl}$; бинарная смесь вода - этанол (47 об.\%); метанол (с массовой долей $99.5 \%$ ).

Концентрацию ПФС в растворах рассчитывали по уравнению градуировочной прямой: для рутина $A=216.54 \cdot c$ и танина $A=407.84 \cdot c$, где $\mathrm{A}-$ оптическая плотность исследуемого раствора, с - концентрация ПФС (рутина или танина), \%; 216.54 и 407.84 - удельный показатель поглощения рутина и танина.

Расчет величины адсорбции (1) и десорбции(2) ПФС (рутин, танин) проводили по формулам:

$$
\begin{gathered}
a=\frac{\left(C_{\text {исх }}-C_{\text {конт }}\right) \cdot V_{a}}{m}, \\
a=\frac{\left(C_{\text {исх }} \cdot V_{a}-C_{\text {конт }} \cdot V_{d}\right)}{m},
\end{gathered}
$$

где $c_{\text {исх }}$ и $c_{\text {конт }}$ - концентрации исходного и контактного раствора аналита $\left(\right.$ ммоль/дм $\left.{ }^{3}\right), V_{a}$ - объем анализируемого раствора, дм ${ }^{3}, V_{d}=\left(V_{\mathrm{a}}-V_{a n}+10\right)$, дм $^{3}, \mathrm{~V}_{\text {ап }}-$ объем раствора израсходованного на определение концентрации ПФС в растворе после адсорбции, дм³ $; \mathrm{m}$ - навеска адсорбента, г.

Степень сорбции и десорбции ПФС на сорбенте рассчитывали по формуле:

$$
R=\frac{\left(C_{u c x}-C_{\text {конт }}\right)}{C_{\text {uсx }}} \cdot 100 \%
$$

Теоретическую обработку полученных изотерм сорбции осуществляли путем линеаризации уравнения Ленгмюра:

$$
a=\frac{a_{\infty} \cdot K \cdot C_{\text {конт }}}{\left(1-K \cdot C_{\text {конт }}\right)}=\frac{a_{\infty} \cdot C_{\text {конт }}}{A+C_{\text {конт }}}
$$

где $a_{\infty}$ - равновесная адсорбция, моль/г; $K$ - константа сорбционного равновесия, $c_{\text {конт }}-$ концентрация ПФС в контактном растворе, моль/дм ${ }^{3}$.

Для графического решения уравнения Ленгмюра приводим к виду:

$$
\frac{C_{\text {конт }}}{a}=\frac{1}{a_{\infty} \cdot K}+\frac{C_{\text {конт }}}{a_{\infty}}
$$

Удельную поверхность $S_{\text {уд, }}$ рассчитывали по формуле: 


$$
S_{y d}=a_{\infty} \cdot N_{A} \cdot S_{c n} \cdot 10^{-20}
$$

где $N_{A}$ - число Авогадро; $S_{c n}$ - молекулярная площадка ПФС: рутина $216.94 \AA$, танина - 396.08 $\AA$ [15], воды - 9.6 ̊, этанола - 25.5 $\AA$ [16].

Физико-химические параметры сорбции ПФС на активном угле рассчитывали по уравнениям Ленгмюра, Фрейндлиха, Дубинина-Радушкевича и БЭТ [17].

\section{Обсуждение результатов}

На рис.2 приведены УФ-спектры проб ГСО рутина, РСО танина и водноэтанольного экстракта травы василька синего (полученного на УЗ-установке) до и после сорбции на активном угле БАУ-А. Значительное снижение интенсивности светопоглощения при 275 нм и 361 нм подтверждает высокую эффективность сорбции ПФС из стандартных растворов и водно-этанольных экстрактов. В табл.2 приведены экспериментально определенные времена достижения сорбционного равновесия ПФС, степени их сорбции (R, \%). Полученные результаты сорбции статистически обработаны, относительная погрешность определения не превышает $10 \%$ при доверительной вероятности 0.95 .

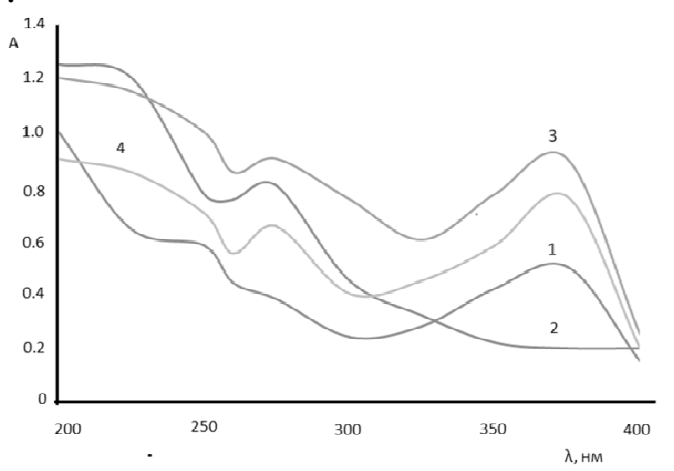

Рис. 2 УФ-спектры: 1 -раствора ГСО рутина; 2 -раствора РСО танина;

3 - водно-этанольный экстракт травы василька синего до сорбции;

4 - водно-этанольный экстракт травы василька синего после сорбции.

Таблица 2. Время достижения (t, мин) сорбционного равновесия, и величина степени сорбции $\mathrm{R}, \%$ ПФС (в пересчете на рутин и танин) на АУ БАУ; $\mathrm{n}=5, \mathrm{P}=0.95$, $\mathrm{S}^{2}=0.0019 \div 0.010 ; \mathrm{S}=0.04 \div 0.11 ; \mathrm{S}_{\mathrm{r}}=0.07 \div 0.25 ; \Delta=4 \div 9 \%$

\begin{tabular}{|c|c|c|c|c|c|c|c|c|c|c|c|c|}
\hline \multirow{3}{*}{$\begin{array}{c}\text { Размер } \\
\text { частиц, } \\
\text { мм }\end{array}$} & \multicolumn{6}{|c|}{ Рутин } & \multicolumn{6}{|c|}{ Танин } \\
\hline & \multicolumn{12}{|c|}{ Сорбция СО } \\
\hline & $\mathrm{t}$ & $\mathrm{R}, \%$ & $\mathrm{t}$ & $\mathrm{R}, \%$ & $\mathrm{t}$ & $\mathrm{R}, \%$ & $\mathrm{t}$, & $\mathrm{R}, \%$ & $\mathrm{t}$ & $\mathrm{R}, \%$ & $\mathrm{t}$ & $\mathrm{R}, \%$ \\
\hline 3.5 & \multirow{3}{*}{5} & $88.5 \pm 0.9$ & \multirow{3}{*}{15} & $89.6 \pm 1.1$ & \multirow{3}{*}{30} & $92.8 \pm 1.2$ & \multirow{3}{*}{5} & $90.0 \pm 1.5$ & \multirow{3}{*}{15} & $92.6 \pm 1.7$ & \multirow{3}{*}{30} & $94.6 \pm 1.8$ \\
\hline $2.8-2.0$ & & $89.3 \pm 1.2$ & & $91.8 \pm 0.7$ & & $93.9 \pm 1.5$ & & $91.8 \pm 1.8$ & & $94.3 \pm 1.9$ & & $95.5 \pm 1.5$ \\
\hline $1.5-1.0$ & & $90.7 \pm 1.6$ & & $94.1 \pm 1.4$ & & $95.7 \pm 1.5$ & & $94.6 \pm 2.4$ & & $96.3 \pm 1.8$ & & $97.4 \pm 1.9$ \\
\hline & \multicolumn{12}{|c|}{ Сорбция из экстракта } \\
\hline 3.5 & \multirow{3}{*}{5} & $85.5 \pm 1.5$ & \multirow{3}{*}{15} & $86.7 \pm 1.5$ & \multirow{3}{*}{30} & $88.7 \pm 1.7$ & \multirow{3}{*}{5} & $87.1 \pm 1.5$ & \multirow{3}{*}{15} & $88.9 \pm 1.3$ & \multirow{3}{*}{30} & $90.6 \pm 1.5$ \\
\hline $2.8-2.0$ & & $87.3 \pm 1.2$ & & $89.8 \pm 0.7$ & & $91.9 \pm 1.5$ & & $88.8 \pm 1.8$ & & $90.3 \pm 1.9$ & & $93.5 \pm 1.5$ \\
\hline $1.5-1.0$ & & $88.7 \pm 1.6$ & & $90.1 \pm 1.4$ & & $93.7 \pm 1.5$ & & $90.6 \pm 2.4$ & & $92.3 \pm 1.8$ & & $95.4 \pm 1.9$ \\
\hline
\end{tabular}

Угольная фракция, размер частиц которой от 1.0-1.5 мм, наиболее полно сорбирует ПФС (93-95 \%) и сорбционное равновесие достигается в течение 15-30 мин. Для выяснения механизма сорбции ПФС построены изотермы сорбции и их линеаризация (рис. 3 а, б и 4 а, б). Полученные изотермы сорбции ПФС на БАУ-А принадлежат к $L$-типу согласно классификации Гиббса. Данная форма изотерм указывает на физическую сорбцию, обусловленную действием ван-дер-ваальсовых сил. По экспериментальным изотермам адсорбции были рассчитаны физико-химические парамет- 
ры с использованием теории мономолекулярной адсорбции (уравнения Фрейдлинха и Ленгмюра), полимолекулярной адсорбции (модель БЭТ) и теории объемного заполнения микропор (уравнение Дубинина-Радушкевича) [17]. Рассчитанные величины параметров адсорбции ПФС приведены в табл. 3.
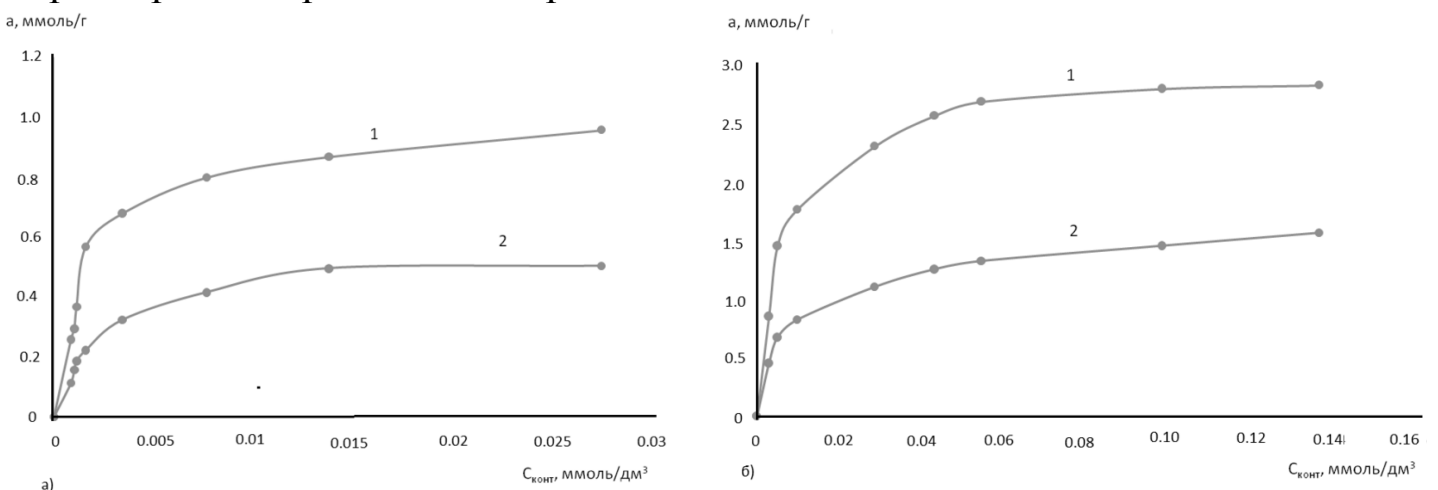

Рис. 3 Изотермы адсорбции полифенольных соединений из стандартных образцов (а): рутин $\mathrm{C}_{\text {исх }}=0.1130$ ммоль $/$ дм $^{3}(1)$, танина $\mathrm{C}_{\text {исх }}=0.0899$ ммоль $/$ дм $^{3}$ (2); водно-этанольный экстракт травы василька синего (б) $\mathrm{C}_{\text {исх }}$ (рутина) $=0.318$
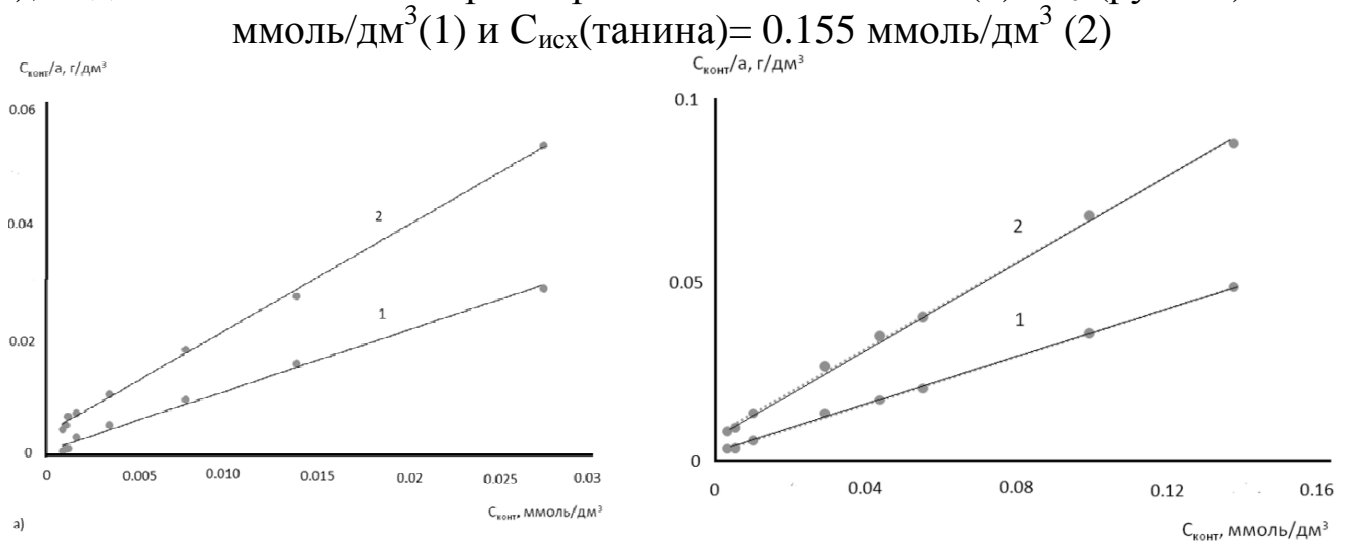

Рис. 4 Линеаризация изотерм сорбции ПФС: водно-этанольные растворы стандартных образцов (а) рутин (1) и танин (2); водно-этанольный экстракт травы василька синего (б) рутин (1) и танин (2).

Таблица 3. Параметры адсорбции рутина и танина АУ БАУ-А по уравнениям Ленгмюра, Фрейндлиха, Дубинина-Радушкевича и БЭТ

\begin{tabular}{|c|c|c|}
\hline Параметры сорбции & Рутин & Танин \\
\hline \multicolumn{3}{|c|}{ по уравнению Ленгмюра } \\
\hline$-\Delta \mathrm{G}^{\mathrm{o}}$, кДж/моль & 29.41 & 2.57 \\
\hline$\alpha_{\infty}$, ммоль/Г & 0.052 & 0.0014 \\
\hline \multicolumn{3}{|c|}{ по уравнению Фрейндлиха } \\
\hline $1 / \mathrm{n}$ & 0.5 & 0.4 \\
\hline $\mathrm{b}$ & $1.76 \cdot 10^{-4}$ & $2.56 \cdot 10^{-5}$ \\
\hline \multicolumn{3}{|c|}{ по уравнению Дубинина-Радушкевич } \\
\hline$\alpha_{0}, \Gamma / \Gamma$ & 0.012 & 0.001 \\
\hline $\mathrm{E}^{\mathrm{o}}$, кДж/моль & 12.54 & 1.97 \\
\hline \multicolumn{3}{|c|}{ по уравнению БЭТ } \\
\hline Q, кДж/моль & 8.54 & 0.36 \\
\hline$\alpha_{\max }$, ммоль/Г & 0.045 & 0.0013 \\
\hline
\end{tabular}

ПФС (рутин и танин) сорбируются за счет ван-дер-ваальсовых сил в микропорах, на что указывают полученные значения энергии Гиббса [18]. В то же время 
функциональные группы на поверхности активного угля (карбонильные, карбоксильные и др.) взаимодействуют с фенольными соединениями с образованием водородных связей.

Десорбция фенольных соединений в статических условиях практически не протекает $(\mathrm{R} \leq 1 \%)$. Поэтому десорбцию ПФС из активного угля БАУ-А осуществляли в динамических условиях. На диаграммах (рис. 5 и 6) представлены зависимости выхода рутина и танина от состава элюирующего раствора.

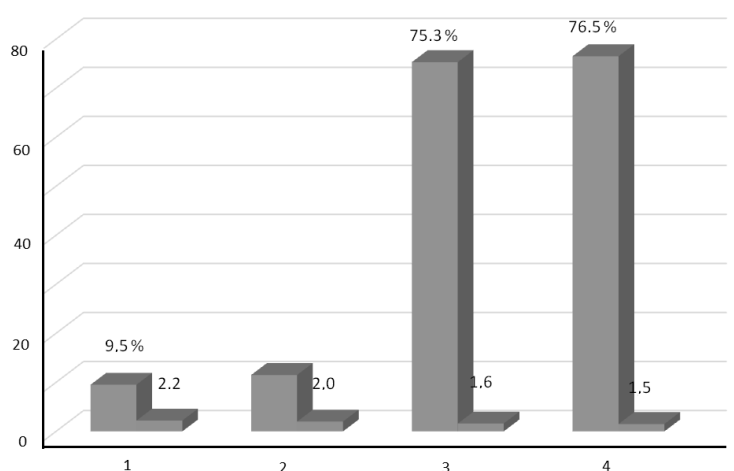

Рис. 5 Диаграмма зависимости выхода рутина от состава элюирующего раствора:1 - дистиллированная вода; 2 - 2 моль/дм ${ }^{3}$ раствор $\mathrm{HCl} ; 3$ - бинарная смесь вода-этанол $\left(\varphi_{2}=47 \%\right) ; 4$ - метанол $(\omega=99.5 \%) .1$ столбец - выход рутина, \%; 2 столбец - продолжительность элюирования, час.

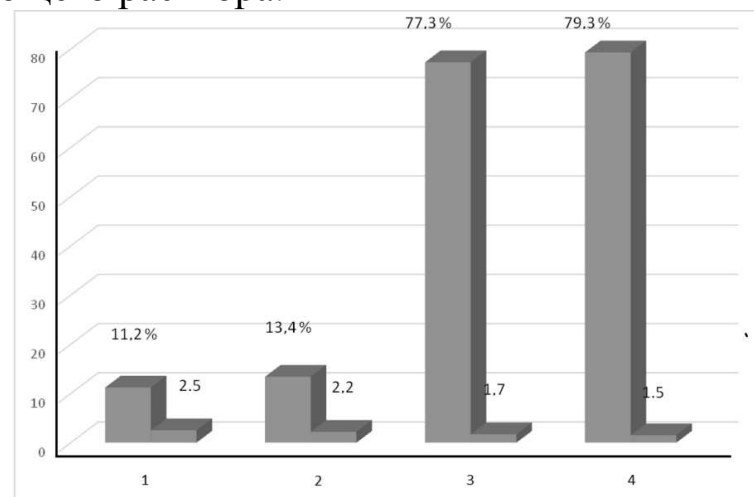

Рис. 6 Диаграмма зависимости выхода танина от состава элюирующего раствора:1 - дистиллированная вода; 2 - 2 моль/дм ${ }^{3}$ раствор $\mathrm{HCl} ; 3$ - бинарная смесь вода-этанол $\left(\varphi_{2}=47 \%\right) ; 4-$ метанол $(\omega=99.5 \%) .1$ столбец - выход танина, \%; 2 столбец - продолжительность элюирования, час.

Диаграммы показывают, что при использовании в качестве элюента бинарной смеси вода - этанол или метанола обеспечивают приемлемый выход рутина и танина 75.3-76.3 и 77.3-79.3\% соответственно, продолжительность элюирования составляет 90 мин.

\section{Заключение}

Таким образом, показано, что активный уголь БАУ-А обладает высокой адсорбционной способностью по отношению к природным полифенольным соединениям. Применение в качестве элюирующего раствора бинарной смеси вода - этанол или метанола позволяет выделить из сорбента до 80 \% ПФС (в пересчете на рутин и танин). Полученные экспериментальные данные позволяют рекомендовать данную марку активного угля в качестве эффективного сорбента для извлечения ПФС из водно-этанольных экстрактов для последующего их выделения.

\section{Список литература}

1. Аверьянова Е.В., Школьникова М.Н. // Вестник КрасГАУ. 2015. № 4. С. 49-54.

2. Минина С.А., Каухова И.Е. Химия и технология фитопрепаратов. М. ГЭОТАР-МЕД. 2004. $560 \mathrm{c}$.

3. Апаева А.В., Ямансарова Э.Т., Куковинец О.С., Зворыгина О.Б. // Вестник Баш- кирского университета. 2016. Т. 21. № 1. С 69-72.

4. Мальцева А.А., Чистякова А.С., Сорокина А.А., Сливкин А.И. // Вестник ВГУ, Серия: Химия. Биология. Фармачия. 2013. № 2. C. 203-205. 
5. Макаева А.З., Оказова 3.П. // Успехи современного естествознания. 2016. № 7. С. 70-75.

6. Орынбасарова К.К. Некоторые лекарственные растения, содержащие флавоноиды сердечно-сосудистого действия и $\mathrm{c}$ Рвитаминной активностью. Учеб. метод пособие. Шымкент, 2009. 57 с.

7. Рудаков О.Б., Подолина Е.А., Рудакова Л.В. // Сорбиионные хроматографические прочессы. 2009. Т. 9. № 2. С. 177-190.

8. Подолина Е.А., Ханина М.А., Рудаков О.Б., Небольсин А.Е. // Вестник ВГУ. Серия: Биология, Химия, Фармация. 2018. № 2. С. 28-35.

9. Zgorka G., Kawka S // J. Pharmaceut. and Biomed. Anal. 2001. No 24. pp. 1065-1072.

10. Suarez B., Picinelli A., Mangas J. // J. Chromatogr. A. 1996. No 727. pp. 203-209.

11. Валов Р.И., Ларионова И.С., Ханина М.Г., Родин А.П. и др. // Фармачия. 2010. № 6. С.29-31.

12. Корольков В.В., Кочеткова М.В., Ларионов О.Г., Емелина С.В. // Сорбционные и хроматографические прочессы. 2008. Т. 8. № 3. C.507-512.

13. Мухин В.М., Клушин В.Н. Производство и применение углеродных адсорбентов: учеб. пособие. М.: Российский химико-

\section{References}

1. Averianova E.V., Shkol'nikova M.N, Herald Krasgau, 2015, No 4, pp. 49-54.

2. Minina S.A., Kauhava I. E. Chemistry and technology of herbal remedies, M., GEOTARMED, 2004, 560 PP.

3. Apaev A.V., Mansurov E.T., Kukovinets O.S., Zvorygina O.B., Bulletin of the Bashkir University, 2016, Vol. 21, No 1, pp 69-72.

4. Maltseva A.A., Chistyakova A.S., Sorokin A.A., Slivkin A.I., Bulletin of VSU, Series: Chemistry. Biology. Pharmacy, 2013, No 2, pp. 203-205.

5. Makaeva A.Z., Okazawa Z.P., Advances in current natural Sciences, 2016, No 7, pp. 70-75.

6. Orynbasarova K.K. Some medicinal plants containing flavonoids of cardiovascular action and with p-vitamin activity. Studies'. Method allowance. Shymkent, 2009. 57 p.

7. Rudakov O.B., Podolina E.A., Rudakova L.V., Sorbtsionnye i khromatograficheskie protsessy, 2009, Vol. 9, No 2, pp. 177-190.

8. Podolina E.A., Khanina M.A., Rudakov O.B., Nebol'sin A.E., Bulletin of VSU. Series: технологический университет им. Д.И. Менделеева. 2012. 308 с.

14. Корж Е.А., Смолин С.К., Клименко Н.А. //Химия и технология воды. 2016. Т. 38. № 4. C. 342-354.

15. Краснова Т.А., Гора Н.В., Голубева Н.С. // Ползуновский вестник. 2014. № 3. С. 237-239.

16. Активные угли. Эластичные сорбенты. Катализаторы, осушители А43 и химические поглотители на их основе: Каталог/ Под общ. Ред. В.М. Мухина. М. Издательский дом «Руда и металлы». 2003. 280 с.

17. Погребняк А.В., Степанова Э.Ф. // Xuмико-фармацевтический журнал. 2003. Т. 37. № 7. С. 36-40.

18. Когановский А.М., Клименко И.А., Левченко Т.М., Рода И.Г. Адсорбция органических веществ из раствора. Л. Химия. 1990. $256 \mathrm{c}$.

19. Герасимов Я.И., Древинг В.П., Еремин Е.Н., Киселев А.В. и др. Курс физической химии. 1964. Т.1. 626 с.

20. Когановский А.М., Клименко Н.А., Левченко Т.М., Марутовский Р.М., Рода И.Г. Очистка и использование сточных вод в промышленном водоснабжении. М. Химия. 1983. $288 \mathrm{c}$.

Biology, Chemistry, Pharmacy, 2018, No 2, pp. 28-35

9. Zgorka G., Kawka S., J. Pharmaceut. and Biomed. Anal., 2001, No 24, pp. 1065-1072.

10. Suarez B., Picinelli A., Mangas J., J. Chromatogr. A, 1996, No 727, pp. 203-209.

11. Shafts R.I., Larionova I.S., Khanin, M.G., Rodin A.P. et al., Pharmacy. 2010, No 6, pp. 29-31.

12. Korolkov V.V., Kochetkova M.V., Larionov O.G. Emelina S.V., Sorbtsionnye i khromatograficheskie protsessy, 2008, Vol. 8, No 3, pp. 507-512.

13. Mukhin V. M., Klushin V. N. Production and application of carbon adsorbents: studies. benefit. - M.: Russian University of chemical technology. D. I. Mendeleev, 2012, 308 p.

14. Korzh E., Smolin S.K., Klimenko N.Ah., Chemistry and water technology, 2016, Vol. 38, No 4, pp. 342-354.

15. Krasnova T.A., Mountain N.In, Golubeva N.S., Polzunovskii]. 2014, No 3, pp. 237-239. 
16. Active coals. Elastic sorbents. Catalysts, dehumidifiers A43 and chemical absorbers based on them: Catalog / under Ls. Ed. V.M. Mukhina, M., Publishing house "Ore and metals", 2003, 280 p.

17. Pogrebnyak A.V., Stepanova E.F., Chemical-pharmaceutical journal, 2003, Vol. 37, No 7, pp. 36-40.

18. Kaganovsky A.M., Klimenko I.A., Levchenko T.M., Roda I.G. Adsorption of organic

Подолина Елена Алексеевна - профессор кафедры безопасности и здоровья, д. хим. н., доцент, Электростальский институт (филиал Московского политехнического университета), Электросталь, 8(49657)4-40-42

Ханина Миниса Абдуллаевна - заведующий кафедрой химии, д. фарм.н., профессор, Государственный гуманитарно-технологический университет г. Орехово-Зуево

Мухин Виктор Михайлович - начальник лаборатории АУЭСиК, д. тех. наук, профессор, Научно-производственное объединение «Неорганика», Электросталь

Рудаков Олег Борисович - заведующий кафедрой химии и химической технологии материалов, д. хим.н., профессор, Воронежский технический университет, Воронеж

Небольсин Александр Егорович - ведущий конструктор, ОАО «Партнер», Воронеж

Козлов Александр Тимофеевич - д.б.н., проф., зав. кафедрой экологии, ${ }^{6}$ Военновоздушная академия имени Н.Е.Жуковского и Ю.А.Гагарина, Воронеж substances from solution. L., Chemistry, 1990, $256 \mathrm{p}$.

19. Gerasimov Ya.I., Dreving V.P., Eremin E.N., Kiselev A.V. et al., Course in physical chemistry. 1964, Vol. 1, 626 p.

20. Kaganovsky A.M., Klimenko N.A. Levchenko T.M., Muratovski R.M., et al., Purification and use of waste-water in industrial water supply. M., Chemistry, 1983, 288 p.

Podolina Elena A. - Professor of the Health and Security Chair, Doctor of Chemistry, associate professor, Elektrostal Institute (Branch of the Moscow Polytechnic University), Eletktrostal, email: podolina70@mail.ru

Khanina Minisa A. - professor and the Head of the Chemistry Chair, Doctor of the Pharmaceuticals Sciences, Humanity-Technological State University, Orekhovo-Zuyevo, e-mail: khanina06@mail.ru

Mukhin Viktor M. - Head of the Laboratory of active carbons, elastic sorbents and catalysts, D. Tech. Sci., Professor, Scientific Production Association "Neorganika", Eletktrostal

Rudakov Oleg B. - Professor and the Head of the Chemistry and Chemical Technology of the Materials Chair, Doctor of Chemistry,Voronezh Technical University, Voronezh, e-mail: robi57@mail.ru

Nebolsin Aleksandr E.- Lead Designer, 4JSC «Partner», Voronezh, e-mail:mks36@mail.ru

Kozlov Alexander T. - Ph. D., prof., Head. Department of Ecology, ${ }^{6}$ Air force Academy named after Professor N. E.Zhukovsky and Y. A. Gagarin, Voronezh 